\title{
MAPEANDO A TRADUÇÃO AUDIOVISUAL ACESSÍVEL NO BRASIL
}

\section{MAPPING ACCESSIBLE AUDIOVISUAL TRANSLATION IN BRAZIL}

\section{Samira Spolidorio*}

\section{RESUMO}

Termos como 'acessibilidade midiática' e 'tradução audiovisual acessível' vem se tornando cada vez mais comuns tanto na área acadêmica quanto na sociedade em geral. Essa popularização deve-se ao aumento significativo da legislação nacional e internacional visando à inclusão das pessoas com deficiências em todas as esferas sociais e, em especial, no que concerne ao âmbito cultural (NAVES et al., 2016). Com essa crescente produção legal, profissional e acadêmica, o Brasil apresenta um sólido e variado portfólio sobre o assunto que não deixa a desejar mesmo quando em comparação com países desenvolvidos. Porém, devido a barreiras linguísticas, nem sempre esse conteúdo recebe o destaque e reconhecimento internacional merecido. Para tentar facilitar a divulgação desse conteúdo, a Plataforma de Acessibilidade Midiática (MAP - Media Accessibility Platform) é uma poderosa ferramenta que visa centralizar informações variadas, desde cursos de formação e notícias até publicações e legislação específica, em um único ambiente digital de livre acesso na internet (GRECO et al., 2016). Infelizmente, até o momento, pouca informação sobre a produção brasileira no assunto foi inserida na plataforma. Então, é interesse desse artigo divulgar não só a MAP em si e destacar a importância de inserir a maior quantidade de dados sobre a produção brasileira sobre tradução audiovisual e acessibilidade midiática em âmbito internacional, mas também apresentar projeto de pesquisa "MAPeando a acessibilidade audiovisual no Brasil e alimentando a plataforma global de acessibilidade midiática (MAP)" do grupo de pesquisa "Tradução Audiovisual: quebrando barreiras linguísticas e de acessibilidade" da Universidade Metodista de Piracicaba (UNIMEP) que, atualmente, dedica-se a esse propósito.

Palavras-chave: tradução audiovisual; acessibilidade; produção audiovisual acessível.

\section{ABSTRACT}

Nowadays, terms such as 'media accessibility' and 'accessible audiovisual translation' are becoming more common both in academia and in society in general. This popularization is due to a significant increase in national and international legislation regarding inclusion of people with disabilities in all social spheres and, in particular, regarding to cultural aspects (NAVES et al., 2016). With such a remarkable increase in legal, professional and academic production, Brazil presents a solid and diverse portfolio that stands out even when compared to the production of developed nations on the same topic. However, because of language barriers, this relevant content does not enjoy the deserved recognition and praise among international researchers. In order to try to change that scenario and help promote this

\footnotetext{
*Universidade Metodista de Piracicaba, Piracicaba, SP. Brasil.samira.spolidorio@gmail.com 
content, the Media Accessibility Platform (MAP) can be a powerful tool as its main goal is to serve as a centralized database. The idea is to gather and organize in a free access and digital interface all different contents related to media accessibility, such as news reports, training courses, academic publication and legislation (GRECO et al., 2016). Unfortunately, so far, very little information regarding the Brazilian production on the topic has been uploaded to the platform. Therefore, our aim here is not only to promote MAP as a key tool for researchers, but also to highlight the importance of uploading as much Brazilian data as possible in order to bring our national content to the spotlight it deserves. Furthermore, we also aim to present the research project "MAPping audiovisual accessibility in Brazil and uploading data to the global Media Accessibility Platform (MAP)" currently been carried out by the research group "Audiovisual Translation: breaking barriers of language and accessibility" at Methodist University of Piracicaba.

Keywords: audiovisual translation; accessibility; accessible audiovisual production.

\section{INTRODUÇÃO}

Já há algum tempo a acessibilidade audiovisual vem sendo o foco de interesse não só da sociedade brasileira como um todo, devido a campanhas de conscientização sobre a legislação nacional sobre o assunto, mas também da academia, que estuda as diferentes modalidades de acessibilidade e prepara profissionais para essa demanda específica do mercado dentro da tradução audiovisual acessível (em especial, com a Legendagem para Surdos e Ensurdecidos, a Audiodescrição e a Janela de LIBRAS).

Crescentes esforços vêm sendo feitos para centralizar tanto as iniciativas legais quanto acadêmicas dentro da área. Podemos citar como exemplos a divulgação de leis e decretos que asseguram o direito a acessibilidade audiovisual por meio de notícias em jornais, revistas, blogs e páginas da internet, além da criação de diversos cursos de tradução audiovisual acessível (TAVa) e, em especial, o lançamento do "Guia de Produções Audiovisuais Acessíveis" (NAVES et al., 2016) pela Secretaria do Audiovisual do Ministério da Cultura.

Toda essa produção brasileira de conteúdo legal, acadêmico e educacional sobre a questão da acessibilidade midiática e a tradução audiovisual é bastante relevante também em contexto internacional. Porém, barreiras linguísticas tendem a limitar a circulação desse conteúdo entre pesquisadores e instituições estrangeiras dificultando o acesso a esse material.

Um dos ambientes em que esse acesso é limitado é a MAP - Media Accessibility Platform (Plataforma de Acessibilidade Midiática), uma plataforma global que tem como objetivo centralizar as informações sobre acessibilidade audiovisual. Nela, informações sobre legislação, pesquisas, treinamentos, e notícias em geral sobre questões ligadas às diversas modalidades de acessibilidade são alimentadas para consulta dentro das várias categorias do site. 
Assim, este artigo visa não só destacar a importância e relevância dessa crescente produção brasileira na área, mas também divulgar a plataforma MAP como uma importante ferramenta para o mapeamento e divulgação do conteúdo sobre acessibilidade audiovisual produzido no Brasil em âmbito internacional.

\section{ACESSIBILIDADE COMO UM 'DIREITO HUMANO' E AS LEIS BRASILEIRAS SOBRE ACESSIBILIDADE}

Desde a Declaração dos Direitos do Homem e do Cidadão, documento elaborado ao final da Revolução Francesa, em 1789, o conceito de 'direitos humanos' tem sido uma discussão cada vez mais central na sociedade. Essa discussão intensificou-se especialmente na segunda metade do último século, depois da criação da Organização das Nações Unidas (ONU) e da Declaração Universal dos Direitos Humanos (DUDH), em 1948, que surgiram depois do final da Segunda Guerra Mundial.

Esse documento, além de combater a violação dos diretos humanos cometida por governos ditatoriais ou separatistas como o apartheid e a segregação americana nos anos 60, visa estabelecer a garantia de oferecimento e cumprimento dos direitos básicos à saúde, segurança, educação e cultura em pé de igualdade entre todos os cidadãos (GRECO, 2016). Nesse contexto, a acessibilidade é um direito fundamental das pessoas com deficiências e uma necessidade da sociedade moderna e igualitária.

Em 2007, a ONU lançou a Convenção Internacional dos Direitos da Pessoa com Deficiência (CIDPD), assinada em 30 de março de 2007 e ratificada em $1^{\circ}$ de agosto 2008. O Brasil, como país membro da ONU e signatário da CIDPD é um dos países comprometidos com a promoção, proteção e garantia dos direitos das pessoas com deficiências estabelecidos pela Convenção.

Porém, mesmo antes da assinatura e ratificação da CIDPD, a legislação brasileira já apresentava elementos voltados para a acessibilidade. As primeiras definições mais explícitas da noção de 'acessibilidade' nas leis brasileiras apareceram no ano 2000, com as Leis n ${ }^{\circ}$ 10.048/00 e 10.098/00 (posteriormente regulamentadas pelo Decreto n ${ }^{0}$ 5.296/04).

Mais especificamente, o artigo $8^{\circ}$ do decreto de 2004 definia acessibilidade em seu inciso I como

condição para utilização, com segurança e autonomia, total ou assistida, dos espaços, mobiliários e equipamentos urbanos, das edificações, dos serviços de transporte e dos 
dispositivos, sistemas e meios de comunicação e informação, por pessoa portadora de deficiência ou com mobilidade reduzida (BRASIL, 2004, grifos nossos)

Embora ainda não haja menção direta às modalidades de tradução audiovisual acessível como são conhecidas hoje (por exemplo, audiodescrição e legendagem para surdos e ensurdecidos), o texto de 2004 já indicava que a ideia de acessibilidade pressuposta pelo decreto incluía os "sistemas e meios de comunicação e informação".

No inciso II, as 'barreiras à acessibilidade' são definidas como "qualquer entrave ou obstáculo que limite ou impeça o acesso, a liberdade de movimento, a circulação com segurança e a possibilidade de as pessoas se comunicarem ou terem acesso à informação" e classificadas em 'urbanísticas', 'nas edificações', 'nos transportes' e 'nas comunicações e informações'.

Essa última classificação apresenta como definição

qualquer entrave ou obstáculo que dificulte ou impossibilite a expressão ou o recebimento de mensagens por intermédio dos dispositivos, meios ou sistemas de comunicação, sejam ou não de massa, bem como aqueles que dificultem ou impossibilitem o acesso à informação (BRASIL, 2004)

O Capítulo VI do decreto de 2004 é inteiramente dedicado a tratar das disposições gerais e específicas relacionadas ao 'Acesso à Informação e à Comunicação' e determina, entre outros elementos, a acessibilidade nos sites da internet, a disponibilização de softwares e hardwares necessários para a inclusão digital de pessoas com deficiência visual, a obrigação das empresas de telefonia fixa e móvel de se adaptar para o uso de pessoas com deficiência auditiva, a 'subtitulação por meio de legenda oculta', 'a janela com intérprete de LIBRAS' e a 'descrição e narração em voz de cenas e imagens', além da necessidade de "tradutores e intérpretes de LIBRAS, ledores, guias-intérpretes, ou tecnologias de informação e comunicação, tais como a transcrição eletrônica simultânea" para eventos ao vivo (BRASIL, 2004).

Essas disposições foram reforçadas pelo Decreto Legislativo $n^{\circ}$ 186/2008 e Decreto Executivo $n^{0}$ 6.949/2009, que estabeleciam as primeiras metas efetivas para adequação da acessibilidade no país em conformidade com as diretrizes da CIDPD, e incorporavam seu conteúdo ao texto da Constituição brasileira.

Segundo Naves et al. (2016), um aspecto que merece destaque é a interpretação dada pela CIDPD e adotada pela legislação brasileira sobre 'deficiência' que "não diz respeito somente ao indivíduo, mas relaciona as barreiras e a interação das pessoas com deficiência com o ambiente" (p. 13). Para as autoras, essa mudança na concepção da deficiência, com a inclusão das barreiras ou entraves que dificultam 
ou impedem a "participação plena e efetiva na sociedade em igualdades de condição com as demais pessoas" (NAVES et al., 2016, p. 13), é bastante positiva e relevante. Assim, mais do que os aspectos de mobilidade urbana e de acesso à comunicação e à informação tratados na legislação anterior, a CIDPD e os decretos de 2008 e 2009 apresentam uma grande ênfase também em elementos relacionados à educação e, em especial, à cultura. E é nesse âmbito que a acessibilidade audiovisual aparece com grande força.

O Plano Nacional da Cultura (PNC), instituído pela Lei 12.343, de 2 de dezembro de 2010, estabelece 53 metas a serem cumpridas e implementadas até 2020 para promoção da diversidade cultural brasileira. Dentre essas 53 metas, muitas têm relação com a produção audiovisual nacional e, para que essa seja verdadeiramente acessível, precisam das modalidades de tradução audiovisual acessível para serem atingidas.

Em 2013, a Agência Nacional do Cinema (ANCINE) apresentou o Plano de Diretrizes e Metas para o Audiovisual (PDMA), no qual a acessibilidade audiovisual para portadores de deficiência auditiva e visual é estabelecida dentro das Diretrizes 6.3 e 6.4 e dos Indicadores 172, 173, 174 e 175, tanto para as salas de cinema quanto para a programação da televisão (de canais abertos e fechados), reforçando o cronograma estabelecido pela Portaria $n^{0} 188$ do Ministério das Comunicações de 24 de março de 2010. Esse cronograma previa a implantação da audiodescrição em uma parcela da programação aberta dos canais de televisão, iniciando-se em 2 horas por semana dentro do prazo de 12 meses e aumentando progressivamente até 20 horas por semana dentro do prazo de 120 meses.

Em 2015, entrou em vigor plenamente a Lei Brasileira da Inclusão da Pessoa com Deficiência (Estatuto da Pessoa com Deficiência), uma legislação bastante abrangente que trata da inclusão nos vários âmbitos sociais, desde emprego, transporte, educação, cultura, lazer sendo a acessibilidade audiovisual muito mencionada em vários desses âmbitos (BRASIL, 2015; NAVES et al., 2016). Um avanço significativo em relação à legislação anterior é que a Lei da Inclusão determina que toda a programação de cinema e televisão ofereça os recursos de acessibilidade, e não mais apenas parcialmente como o cronograma da Portaria n ${ }^{\circ} 188$ estabelecia.

Assim, é evidente que o Brasil tem um aparato legal bastante desenvolvido em relação não só à acessibilidade, mas também em relação à acessibilidade audiovisual em particular. Com isso, impulsionado tanto pela exigência da legislação quando pela conscientização social, o mercado audiovisual vem tentando se adaptar a essas mudanças. Porém, ao acatar parâmetros técnicos e padronizações estrangeiras, deixa-se de levar em conta o contexto singular da acessibilidade no Brasil. Assim, 
é imperativo não só que pesquisas focadas no contexto brasileiro continuem a ser desenvolvidas, mas também que essas pesquisas possam ser divulgadas em âmbito mundial.

Contudo, o pouco volume de divulgação em âmbito internacional faz com que o acesso da comunidade acadêmica mundial a essas importantes contribuições seja dificultado. Portanto, é interesse desta pesquisa ressaltar a importância de uma maior divulgação do conteúdo brasileiro dentro do cenário global e como a inclusão dos dados mapeados sobre o conteúdo de acessibilidade audiovisual produzidos no Brasil dentro da plataforma MAP pode ser um passo relevante nessa direção.

\section{TRADUÇÃO AUDIOVISUAL ACESSÍVEL NO BRASIL}

A prática da tradução é muito antiga, mas a área de estudos de tradução é relativamente nova. O mesmo acontece com a tradução audiovisual (TAV). Como bem explica Romero-Fresco (2013, p. 205), "mesmo antes da introdução do som no cinema, filmes mudos precisavam da tradução dos intertítulos usados para expressar os diálogos ou a narração" ${ }^{\prime 1}$. Assim, embora seja possível datar o nascimento da tradução pelo surgimento do cinema mudo, que antecede em muito o cinema falado e ainda mais a televisão, só depois da virada do milênio é que a tradução audiovisual começou a receber atenção dentro da academia.

É evidente que desde o final do século XIX não só o cinema como também a TAV evoluiu muito para acompanhar as demandas criadas pelas novas mídias audiovisuais, como o cinema falado, a televisão, VHS, DVDs e Blue Rays e, atualmente, os vídeos em páginas da internet. Gambier (2001), um dos pioneiros em abordar questões sobre a tradução audiovisual em seus estudos, afirma que a mudança imposta pelo advento de novas tecnologias e a evolução nas diferentes mídias hoje provocou mudanças também na maneira como pensamos, analisamos e teorizamos esses novos objetos midiáticos, e deve ser levada em consideração ao formularmos nossas reflexões acerca do uso da linguagem nos meios multimidiáticos.

Para o autor, "a mídia nos força a reformular certas questões e a redefinir certos conceitos que por muito tempo foram tidos como certezas absolutas. Por exemplo, os conceitos de 'texto' e de 'sentido"' (GAMBIER, 2001 p. 16 ). Em consonância com essa necessidade de revisar alguns desses conceitos mais básicos indicada por Gambier, Diaz-Cintas, em "In search of a theoretical framework

1. A menos que explicitamente especificado o contrário, todas as traduções de textos em inglês citados neste artigo são de nossa autoria. 
for the study of audiovisual translation" (2004), afirma que é imperativo que os estudos sobre TAV se sustentem por si sós e produzam um aporte teórico próprio, justamente por terem um objeto de estudo tão particular.

Segundo o autor, para pensar a TAV de uma forma mais específica e não apenas segundo a adaptação de conceitos desenvolvidos para a tradução de textos escritos, a aproximação com outras áreas de estudo - como, por exemplo, Estudos de Cinema -, foi de grande ajuda para entender como as obras audiovisuais são produzidas. Também é possível encontrar menções à nomenclatura "Estudos Fílmicos", mas o termo "Estudos de Cinema" parece ser o nome mais usado em português para a área de Film Studies. É válido ressaltar que, em muitas universidades do Brasil, a área já se apresenta como "Estudos de Cinema e Audiovisual", seguindo a delimitação usada pela SOCINE (Sociedade Brasileira de Estudos de Cinema e Audiovisual <http://www2.socine.org.br/>).

Dentre os autores que abordam a questão da TAV a partir dessas outras perspectivas teóricas na tentativa de mesclar áreas de estudos diversas, é importante ressaltar os estudos de Pablo Romero-Fresco (2013) em relação à acessibilidade no processo de produção fílmica. Para o autor, a tradução audiovisual deveria ser um aspecto a ser considerado já no estágio de concepção do produto audiovisual, fazendo com que o planejamento das cenas leve em consideração o fato de que essas cenas terão que passar por uma ou mais modalidades de TAV.

Vale lembrar que essa necessidade de entender a tradução audiovisual e, em especial, a tradução audiovisual acessível como parte integrante do processo de produção audiovisual também é destacada pelo PDMA da ANCINE, também lançado em 2013, que afirma que

a acessibilidade deve ser incorporada desde o desenho do projeto e estar presente em todas as fases da produção e distribuição. Portanto, não é mais admissível tratar a acessibilidade como acessório, complemento ou adaptação a posteriori (apud NAVES et al., 2016).

Essa proximidade nas datas mencionadas acima nos permite constatar que as exigências e recomendações para produção audiovisual brasileira estão em consonância com os estudos acadêmicos mais relevantes da área, o que só reforça a importância de divulgação da produção acadêmica e profissional brasileira também em âmbito internacional.

Em 2015, Diaz-Cintas propõe-se, em conjunto com Josélia Neves, revisitar e atualizar a questão do aporte teórico específico para a TAV iniciada em seu texto de 2004. Depois de mais de uma década, os autores afirmam que a "TAV é vista por muitos estudos como ramo mais próspero e bem-sucedido dos Estudos da 
Tradução" (DIAZ-CINTAS, NEVES, 2015, p.1), atribuindo essa notoriedade à intrínseca relação com a tecnologia. Para eles,

é claramente visível que a TAV evoluiu muito desde que começou a ganhar reconhecimento acadêmico em meados da década de 1990. Também é importante reconhecer que essa frutífera área de estudos de tradução tem usado conhecimentos de uma série de outras disciplinas, como, por exemplo, neurociência, engenharia, psicologia, sociologia, entre outras. Com todos esses novos rumos que a TAV tem trilhado, principalmente no que concerne à acessibilidade, mas também graças à rápida evolução envolvendo a tecnologia e as mudanças sociais, parece legítimo questionar se a TAV não teria ultrapassado os limites da Tradução e dos Estudos da Tradução para se tornar uma nova disciplina em si mesma, ou pelo menos, certamente uma interdisciplina (DIAS-CINTAS; NEVES, 2015, p.2).

Como os próprios autores admitem, a audaciosa proposta de ver a TAV como uma área independente de pesquisa ainda está longe de se realizar. Contudo, é impossível negar que cada vez mais estudos têm como foco várias modalidades de TAV, expandindo ainda mais o repertório teórico disponível e fortalecendo esse campo de pesquisa que está longe de se esgotar.

Com essa constante reformulação de conceitos teóricos a partir de questões impostas pelas novas mídias e práticas da língua(gem), além da necessidade da tradução para transpassar uma barreira linguística existente, é importante sempre levar em conta o surgimento de diferentes modalidades de TAV que vão além das duas mais conhecidas (legendagem e dublagem).

As modalidades inicialmente citadas por Gambier (2001) são mais numerosas e incluem não só modalidades de screen translation (ou seja, TAV relacionada à tela do cinema, da televisão e/ou do computador), mas também modalidades presenciais nas quais existam uma combinação de aspectos visuais e sonoros (por isso, justificando a inserção em "audiovisual").

O autor lista, exatamente nesta ordem, as seguintes modalidades: legendagem interlinguística ou legenda aberta (interlingual subtitling ou open caption), legendagem bilíngue (bilingual subtitling), dublagem (dubbing), dublagem intralingual (intralingual dubbing), interpretação consecutiva (consecutive interpreting), interpretação simultânea (simultaneous interpreting), interpretação de sinais (sign language interpreting), voice-over ou meia-dublagem (voice over ou balf dubbing), comentário livre (free commentary), tradução a prima vista ou simultânea (simultaneous or sight translation), produção multilinguística (multilingual production), legendagem intralinguística ou closed caption (intralingual subtitling ou closed caption), tradução de roteiro (scenario/script translation), legendagem ao vivo ou em tempo real (live or real time subtitling), supralegendagem ou legendagem eletrônica (surtitling) e audiodescrição (audiodescription). 
Em "Questões terminológico-conceituais no campo da tradução audiovisual (TAV)", Franco e Araújo (2011) criticam a divisão apresentada acima por Gambier (2001), afirmando que algumas modalidades relacionadas à interpretação presencial como a consecutiva, a simultânea, a prima-vista e a de língua de sinais já podem ser classificadas dentro de outra área de estudo independente, os Estudos da Interpretação, e que, portanto, não competem aos estudos propostos pela TAV.

Assim, para as autoras, a TAV deve limitar-se às modalidades antes definidas por Gambier (2001) como screen translation, ou seja, aquelas que fazem uso de uma tela (de cinema, de televisão ou de computador), podendo ser inter ou intraligual e apresentar-se nas modalidades oral ou escrita. A saber, as modalidades escritas incluem legendagem para ouvintes, legendagem para surdos e ensurdecidos e a legendagem eletrônica, enquanto as modalidades orais incluem a dublagem, o voiceover, a narração (ou voice-off) e a audiodescrição (FRANCO; ARAUJO, 2011):

- Legendagem para Ouvintes (LO), mais conhecida apenas como "legendagem", é o processo de transpor por escrito os diálogos de um vídeo, atentando-se para os parâmetros técnicos de limites de caracteres e de linhas permitidos bem como a velocidade de legenda indicada para o público-alvo. Para isso, é necessário dominar uma série de estratégias de tradução como condensação, segmentação para quebra de linha, redução/adição, etc. Esse tipo de legendagem não só representa o maior nicho do mercado de legendagem no Brasil, mas também determina os parâmetros básicos para os outros tipos de legendagem;

- Legendagem para Surdos e Ensurdecidos (LSE) preocupa-se em transpor por escrito não só as informações, levando em conta os parâmetros da legendagem para ouvintes, mas incluir também barulhos, ruídos, música da trilha sonora ou de fundo, ou ainda qualquer outra informação sonora relevante para a compreensão da cena. É importante diferenciar a LSE do closed caption, um tipo de legenda fechada (ativada no controle remoto ou no menu do DVD ou plataforma de visualização - em oposição à legenda aberta, 'queimada' diretamente no vídeo e não pode ser excluída) que usa o modelo americano de teletexto, apresentando a fala integral subindo na tela e podendo chegar até 3 linhas de legenda;

- Legendagem Eletrônica (surtitling), usada em teatros para peças e óperas, também é conhecida como 'supralegendas' em referência à posição acima do palco em que aparece. Contudo, as autoras justificam a classificação como 'legendagem eletrônica', por ser o termo mais usado nos meios culturais que fazem uso dessa modalidade;

- Dublagem é a substituição dos diálogos em áudio de uma língua para outra, eliminando por completo a presença do idioma estrangeiro e respeitando critérios 
de sincronia labial a fim de criar uma impressão de naturalidade. É a modalidade mais comum no Brasil e tem sua utilização definida pela Lei 4.117/62 (decreto de Jânio Quadros), que determina que todos os produtos audiovisuais estrangeiros veiculados na televisão aberta devem ser dublados;

- Voice-over, assim como a dublagem, é uma tradução audiovisual interlingual, mas não há a completa substituição do áudio original, apenas uma sobreposição do áudio traduzido sobre o áudio original, que ainda pode ser ouvido 'ao fundo'. Uma vez que não há a intenção de manter a ilusão de naturalidade, pois é possível ouvir o áudio original ao fundo, a preocupação com a sincronia labial é bem menor. Essa modalidade é, em geral, usada para produtos audiovisuais de não-ficção da televisão por assinatura;

- Narração acontece quando se tem 'um falante invisível', portanto, sem qualquer tentativa de sincronia labial. Pode ser usada em conjunto com a dublagem ou com o voice-over, tanto em produtos de ficção quanto em não-ficção;

- Audiodescrição é a tradução oral (podendo ser inter ou intralingual) de estímulos visuais. Pode ser de produtos audiovisuais da televisão e cinema, mas também de peça de teatro, espetáculo de dança, exibições artísticas, etc. É destinada à acessibilidade de pessoas com deficiência visual.

Dentre essas categorias acima, enquadram-se na tradução audiovisual acessível a Legendagem para Surdos e Ensurdecidos, a Legendagem Eletrônica e a Audiodescrição. Porém, no "Guia de Produções Audiovisuais Acessíveis" (NAVES et al., 2016) e em outros estudos mais recentes, a Janela de LIBRAS também é considerada uma modalidade de tradução audiovisual acessível. Como veremos mais adiante neste artigo, a Plataforma de Acessibilidade Midiática apresenta ainda uma outra divisão com outras modalidades não incluídas nem no artigo de Araújo e Franco (2011) nem no Guia (NAVES et al., 2016), pois considera, além da acessibilidade das pessoas com alguma deficiência, também a acessibilidade linguística de quem não consegue compreender o produto audiovisual em seu idioma original.

Villela (2017) afirma que os estudos de tradução audiovisual acessível no Brasil têm se destacado de forma significativa na última década, porém, o interesse e desenvolvimento na área não ficaram restritos apenas ao meio acadêmico e a acessibilidade audiovisual é um termo cada vez mais recorrente também no mercado audiovisual. Como exemplo, a autora cita uma variedade de festivais de cinema, espetáculos de teatro e outros espaços culturais como museus, galerias e até festas típicas de rua como o carnaval que já incluem conteúdo acessível. Esse aumento da produção não só teórica, mas também prática ressalta a importância da tradução audiovisual acessível não só como objeto de estudo digno da academia, 
mas também como um aspecto cada vez mais presente na nossa sociedade e fator importante no mercado de trabalho da tradução.

Dentro da área acadêmica, podemos destacar três universidades brasileiras que têm se sobressaído na produção de pesquisa especificamente voltada para a tradução audiovisual acessível: a Universidade Estadual do Ceará, com o Laboratório de Tradução Audiovisual (LATAV) e o grupo de pesquisa em Legendagem e Audiodescrição (LEAD); a Universidade de Brasília, com o programa de pósgraduação em Estudos da Tradução (POSTRAD) e o Laboratório de Linguística de Língua Brasileira de Sinais (LabLIBRAS); e a Universidade Estadual Paulista 'Júlio de Mesquita Filho' (UNESP-Bauru), com o grupo de pesquisa em Mídia Acessível e Tradução Audiovisual (MATAV).

Apenas a título de informação, podemos citar dados relevantes como, além dos mencionados acima e de acordo com o Diretório de Grupos de Pesquisa do Brasil da Plataforma Lattes-CNPq, existem no país um total de 11 grupos de pesquisa oficialmente cadastrados que são relacionados à 'tradução audiovisual'. Desses, oito incluem pelo menos uma das modalidades de tradução audiovisual acessível no nome, descrição e/ou nas palavras-chave do grupo.

Da mesma forma, numa busca simples no Banco de Teses e Dissertações da CAPES por pesquisas com a palavra-chave 'legendagem', foram encontradas 64 pesquisas de stricto sensu entre 2009 e 2016; 62 resultados com a palavra-chave 'audiodescrição' para os anos entre 2011 e 2016; e impressionantes 146 pesquisas para a combinação de palavras-chave 'legendagem' + 'surdos'.

Isso, claro, sem contar um crescente número de publicações de artigos em periódicos, além de livros e capítulos de livros que só reiteram a relevância da produção acadêmica brasileira dentro da área de tradução audiovisual e da tradução audiovisual acessível. Desse conteúdo todo, pouco mais de uma dúzia de entradas, indicando artigos e livros (ou capítulos de livros), foram inseridas na MAP até o momento, deixando de fora a considerável contribuição de pesquisadores brasileiros para a área.

\section{APRESENTANDO A MAP}

A Plataforma de Acessibilidade Midiática (Media Accessibility Platform - MAP) foi idealizada por quatro importantes pesquisadores internacionais das áreas de tradução audiovisual e de acessibilidade midiática (Gian Maria Greco, Anna Matamala, Pilar Orero e Pablo Romero-Fresco) e tem como objetivo principal ser 
um banco de dados centralizador de informações sobre acessibilidade midiática e tradução audiovisual acessível em nível mundial.

A plataforma foi lançada em outubro de 2016 e, em novembro do mesmo ano, os autores compareceram à conferência europeia sobre novas mídias (9th New European Media Summit), realizada na cidade do Porto, em Portugal, para divulgar a iniciativa. Na palestra que serviu como 'lançamento' da plataforma, os idealizadores começaram apresentando o conceito de 'acessibilidade midiática' como uma área de pesquisa, indicando as múltiplas possibilidades de investigação advindas de diferentes campos do saber que com ela têm ligação. As informações apresentadas na palestra foram, posteriormente, divulgadas na forma de artigo completo publicado nos anais da conferência, possibilitando seu uso como importante fonte bibliográfica.

Por ser um conceito ainda em construção e não tão bem delimitado na literatura da área, os autores começam apresentando a 'acessibilidade midiática' que, a saber, é o campo de estudo que se refere às "teorias, práticas, serviços, tecnologias e instrumentos que fornecem acesso a produtos midiáticos, serviços e ambientes para pessoas que não podem, de forma integral ou parcial, acessar o conteúdo em sua forma original" (GRECO et al., 2016 ).

Além de um campo de estudo frutífero, a acessibilidade midiática também tem um grande papel social e cultural, relacionada às diversas leis e práticas de inclusão. Segundo Greco et al. (2016) é possível ver o envolvimento de várias esferas e instituições com a questão da acessibilidade midiática, como, por exemplo:

- leis nacionais e internacionais que asseguram o direito ao conteúdo acessível e as instituições regulamentadoras que organizam, orientam e padronizam esse oferecimento;

- organizações sociais que conscientizam o restante da população para a importância da acessibilidade midiática para uma sociedade mais justa e inclusiva;

- indústrias que desenvolvem não só os novos serviços a serem prestados, mas também a tecnologia necessária para isso;

- universidades e outros ambientes de formação que preparam profissionais conscientes e com as habilidades e capacidades necessárias;

- estudos acadêmicos que testam e avaliam os serviços, desenvolvendo o quadro teórico e a recepção desses serviços e produtos.

Para os autores, não só de grande importância e relevância, a área também se encontra em rápido desenvolvimento. Segundo dados coletados da plataforma de pesquisa especializada em conteúdo acadêmico, Google Acadêmico, a diferença do 
número de pesquisas publicadas entre os anos 2000 e 2007 e entre 2008 e 2015 é expressiva. Abaixo, a tradução da tabela apresentada pelos autores:

Tabela 1: resultados da pesquisa no Google Acadêmico em 31/10/2016

\begin{tabular}{|c|c|c|}
\hline PALAVRAS-CHAVE DA PESQUISA & 2000-2007 & 2008-2015 \\
\hline "áudio descrição" + acessibilidade & 398 & 1.680 \\
\hline legendagem + acessibilidade & 464 & 2.130 \\
\hline Legendas + acessibilidade & 2.130 & 7.320 \\
\hline Legendar + acessibilidade & 1.620 & 4.080 \\
\hline "acessibilidade midiática" & 265 & 1.070 \\
\hline Legendas + acessibilidade + idosos & 428 & 1.240 \\
\hline
\end{tabular}

Fonte: Greco et al. (2016, p. 1)

Os números apresentados na tabela acima, que são referentes apenas as palavras-chave em língua inglesa ${ }^{2}$ e resultantes de uma ferramenta de busca específica, indicam a rapidez com que os estudos em acessibilidade midiática têm avançado e se desenvolvido. Se considerássemos as produções em outras línguas que não a língua inglesa e a busca em outras ferramentas que não o Google Acadêmico, o número com certeza seria ainda maior.

A expressividade desses resultados, juntamente com os avanços também no mercado de trabalho e no âmbito social, destaca que a quantidade de conteúdo disponível sobre o assunto não só é bastante grande, mas como também cresce exponencialmente. Porém, os autores alertam que esse conteúdo todo está 'fragmentado' em diferentes bancos de dados e em diferentes idiomas, o que dificulta a descoberta e organização desse material todo.

Os autores descrevem dois obstáculos sérios que dificultam o acesso e divulgação do conteúdo produzido na área da acessibilidade midiática, nomeandoos de problema da 'Biblioteca de Babel' e efeito de 'Reinventar a Roda'. O problema da 'Biblioteca de Babel' é definido pelos autores como

um cenário em que a quantidade de dados produzidos é tão grande, porém não organizados, que há o risco de que informações úteis fiquem soterradas debaixo de pilhas e mais pilhas de informações não-relacionadas (GRECO et al., 2016, p.2)

2. Em língua inglesa, existem duas palavras para 'legenda': 'subtitles' e 'captions', sendo, em geral, 'subtitles' mais usada para as legendas de produtos audiovisuais (vídeos, filmes, etc.) e 'captions' para as legendas de imagens estáticas (fotos, imagens, etc). Em língua portuguesa, por não termos essa diferenciação, optou-se por traduzir por 'legendas' e 'legendar' apenas para indicar uma sutil diferença e salvaguardar a expressividade dos números apresentados na tabela. 
Nesse cenário, correr-se-ia o risco de 'gerar uma quantidade de informação muito grande para ser conhecida' (BURDON; ANDREJEVIC, 2014 apud GRECO et al., 2016), o que, por sua vez, dificultaria a intertextualidade entre pesquisas e a cooperação entre instituições pesquisadoras. Essa fragmentação e compartimentalização do conhecimento produzido e a dificuldade em encontrar o conteúdo já existente poderiam causar o efeito de 'Reinventar a Roda'.

Para os autores, esse efeito pode ser entendido como a necessidade de várias pesquisas precisarem 'começar do zero' simplesmente por não terem conhecimento ou acesso a pesquisas anteriores sobre o assunto e que já abordaram alguns dos pontos estudados. Assim, ao invés de focar-se em avanços significativos para a área, cada pesquisa precisa retornar ao início e dar conta de aspectos fundamentais antes de fazer contribuições novas.

Como exemplo, os autores citam vários estudos realizados entre 2015 e 2016 que abordam elementos muito similares, todos afirmando categoricamente que são importantes e relevantes os estudos em acessibilidade midiática e também alertando que esse tema precisa ser mais estudado, não só em relação à acessibilidade do conteúdo televisivo, mas também da mídia digital como um todo.

Dessa forma, o efeito da 'Reinvenção da Roda' causa um número alto de pesquisas muito similares e que pouco contribuem para os avanços da área por terem que sempre partir do princípio e reestabelecer questões fundamentais. Para os autores, uma vez que essa informação toda estivesse disponível e organizada num só local e de fácil acesso, as pesquisas poderiam avançar com maior rapidez e relevância.

Para isso, a MAP foi idealizada a fim de "desenvolver uma ferramenta ou grupo de ferramentas para facilitar a busca de conteúdo e incentivar a reutilização e transferência de conhecimento" (GRECO et al., 2016, p.2). Com a ajuda de estratégias de gerenciamento de informação, a MAP busca:

- criar um repositório central para informação, com funcionalidades de busca;

- estruturar a informação por meio de indexação, categorização e agrupamento;

- estabelecer ferramentas e funções de apoio;

- mapear o conhecimento.

Assim nasceu a MAP, "uma ferramenta especialmente projetada para ajudar a reduzir os problemas de compartilhamento, reutilização e transferência de conhecimento" (GRECO et al., 2016, p.2), um site que funciona não só como um 
banco de dados, mas também como ferramenta de buscas para conteúdos diversos relacionados à acessibilidade midiática.

A plataforma foi elaborada dentro do software-livre Drupal 8.2 e tem sua base de dados modelada a partir da MySQL 5.6, o que significa dizer que ela parte de uma estrutura pré-definida, sendo esta um conjunto de módulos pré-desenvolvidos do software Drupal, juntamente com um código de programação próprio para a inserção de bancos de dados e bibliotecas externas.

O conteúdo é organizado dentro de uma taxonomia composta pela tabulação de dados inter-relacionados por diferentes elementos que podem ser agrupados, categorizados e indexados, além de facilmente buscados e recuperados. Na imagem abaixo, são apresentadas as abas do site com as diferentes categorias:

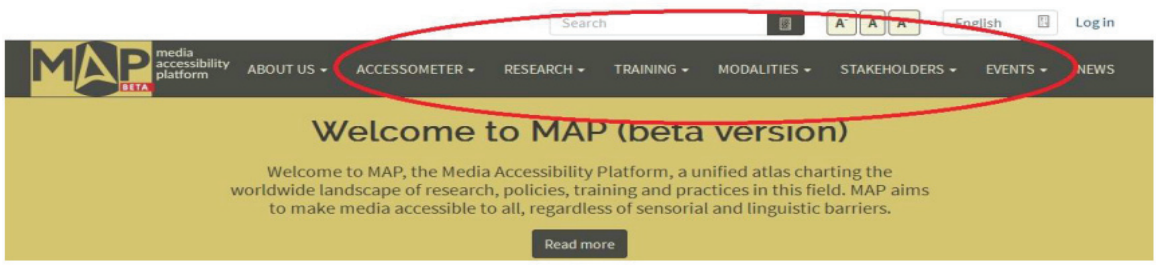

Figura 1. captura de tela das abas do site da MAP

Fonte: Greco et al. $(2016$, p.3)

A plataforma é organizada da seguinte forma:

- About Us (Sobre Nós), em que são listados os submenus que apresentam a 'Visão e Missão' do site, o que é 'Acessibilidade Midiática e os serviços acessíveis', quem são os idealizadores do site, quem são os contribuidores da plataforma, informações sobre como contribuir e um formulário para contato;

- Accessometer (Acessômetro), em que constam itens de legislação e documentação oficial para orientação e padronização de cada país;

- Research (Pesquisa), em que constam projetos, publicações e apresentações em conferências no mundo todo;

- Training (Treinamento), em que constam os cursos de formação para acessibilidade midiática, divididos por cursos universitários, cursos online e cursos profissionalizantes;

- Modalities (Modalidades), em que o conteúdo pode ser acessado a partir das diversas modalidades de acessibilidade audiovisual ${ }_{i}$ 
- Stakeholders (Partes Interessadas), em que constam as empresas e instituições (exceto universidades) envolvidas ou relacionadas com acessibilidade midiática;

- Events (Eventos), em que constam as conferências, seminários, congressos, palestras, oficinas e tutoriais na área,

- News (Notícias), em que constam as matérias, reportagens, notas e notícias publicadas na mídia especializada ou não sobre o assunto.

Segundo os autores, por ordem de importância e relevância, os primeiros itens a serem abordados e terem os seus dados inseridos seriam os dados relativos ao Acessômetro, em especial à legislação e documentação oficial de orientação e de padronização. Em outubro de 2016, à época da conferência de lançamento, o quadro do Acessômetro apresentava-se da seguinte forma:

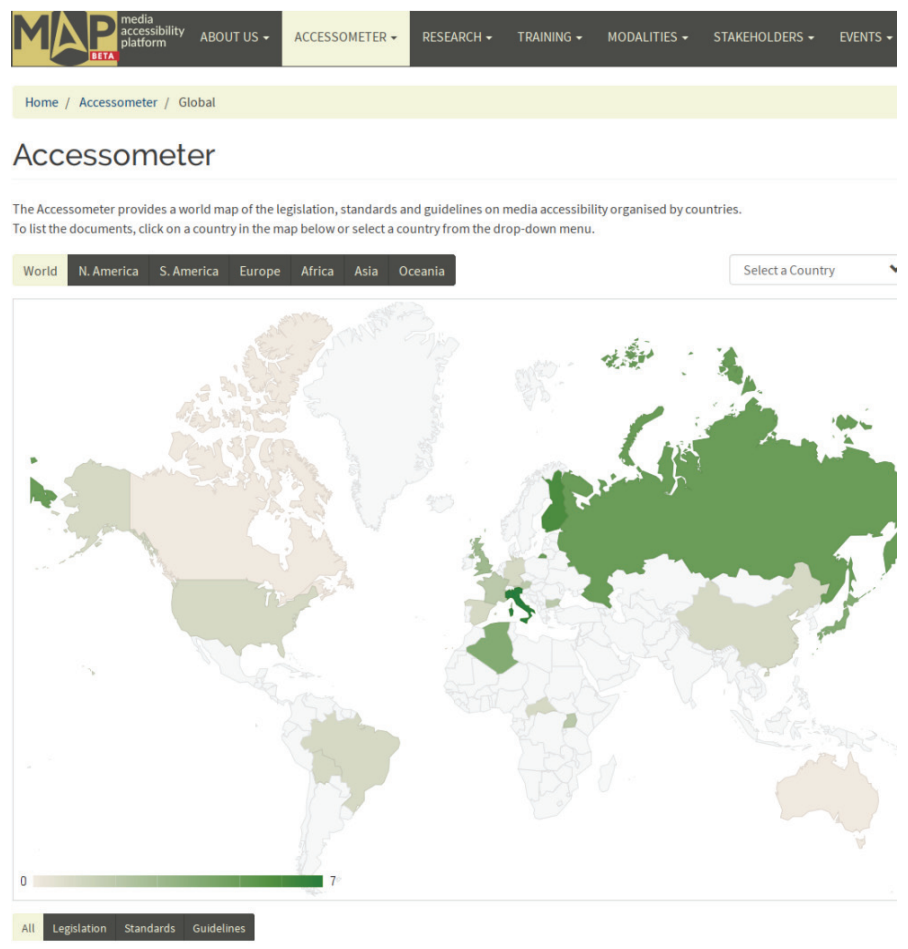

Figura 2. captura de tela do Acessômetro em 31/10/2016

Fonte: Greco et al. $(2016$, p.5)

No mapa acima, as áreas em verde destacam, numa escala de 0 a 7 , a quantidade de itens existentes em cada país referentes à legislação e a documentos oficiais 
de padronização e orientação. Como se pode notar pela cor cinza apresentada no mapa do Brasil, até aquele momento, não havia nenhuma informação inserida no site sobre o país.

A primeira fase da versão beta da MAP ocorreu entre outubro de 2016 e fevereiro de $2017^{3}$ e contou com um número reduzido de participantes para facilitar o controle e comunicação entre os participantes. Nessa fase, a MAP era atualizada pelos quatro pesquisadores idealizadores da plataforma e mais oito colaboradores externos que compilavam e inseriam manualmente a maior quantidade possível dos dados encontrados na Plataforma. Os dados inseridos eram então enviados para 'revisão' pelo webmaster que verificava se os campos haviam sido corretamente preenchidos antes de liberar a postagem de cada item na plataforma.

Já nesta primeira fase, mesmo com uma equipe e um tempo reduzidos, os idealizadores e colaboradores da plataforma conseguiram reunir uma quantidade de dados significativa em relação a outros países e, em 28 de abril de 2017, o mapa do Acessômetro apresentava-se da seguinte forma:

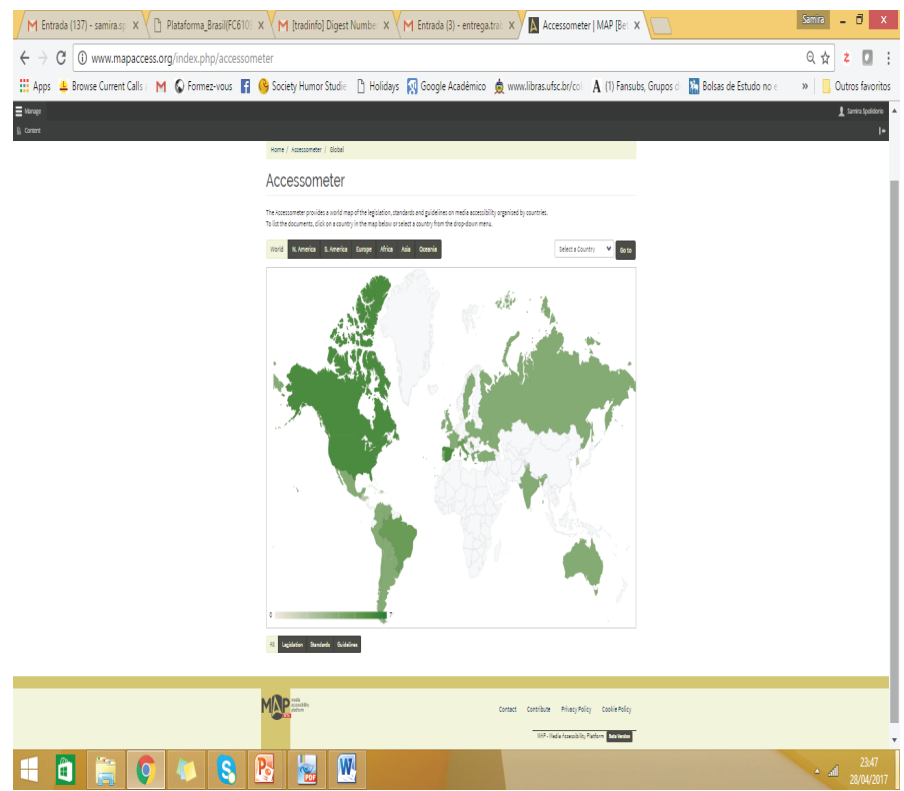

Figura 3. captura de tela do Acessômetro da MAP em 28/04/2017

Fonte: a autora

3. Depois de uma pausa em março e abril para analisar os resultados da primeira fase e considerar o feedback oferecido pelos participantes, a segunda fase terá início em maio e visa ampliar a rede de colaboradores para coletar e inserir os dados na plataforma. 
Na comparação entre as duas imagens acima é possível perceber como boa parte dos países da América do Norte e da América do Sul tiveram seus dados incluídos, além de outros países da Europa, Ásia e Oceania, modificando o mapa apresentado na Figura 2. Todavia, a totalidade dos países da África e do Oriente Médio continua sem informação, assim como também uma considerável parcela dos países asiáticos.

Especificamente sobre o Brasil, ao acessarmos a página do país no Acessômetro, encontramos apenas quatro itens de legislação e um item de orientação. São listados como legislação a Lei do Audiovisual n ${ }^{\circ}$ 8.685/93, a Lei Brasileira da Inclusão da Pessoa com Deficiência n ${ }^{\circ} 13.146 / 15$, o Decreto Legislativo no ${ }^{\circ} 186 / 08$ e o Decreto Executivo $n^{\circ}$ 6.949/09. Os decretos, como já mencionado, são os que implementam e regulamentam a CIDPD da ONU, deixando de fora não só todos os outros decretos, leis e portarias apresentados na primeira parte desse artigo, como também outros itens de legislação (nacional, estadual e municipal) existentes que não foram mencionados aqui.

Podemos ver, na Figura 4, que a categoria de orientação apresenta o "Guia para Produções Audiovisuais Accessíveis", lançado pela Secretaria do Audiovisual do Ministério da Cultura em 2016, mas não há nenhum documento de regulamentação e padronização inserido. A instituição brasileira responsável pela elaboração da regulamentação e padronização é a Associação Brasileira de Normas Técnicas (ABNT); contudo, até a última consulta realizada para a elaboração deste artigo (28/04/2017), não foi encontrado um documento oficial que tratasse da acessibilidade midiática. 


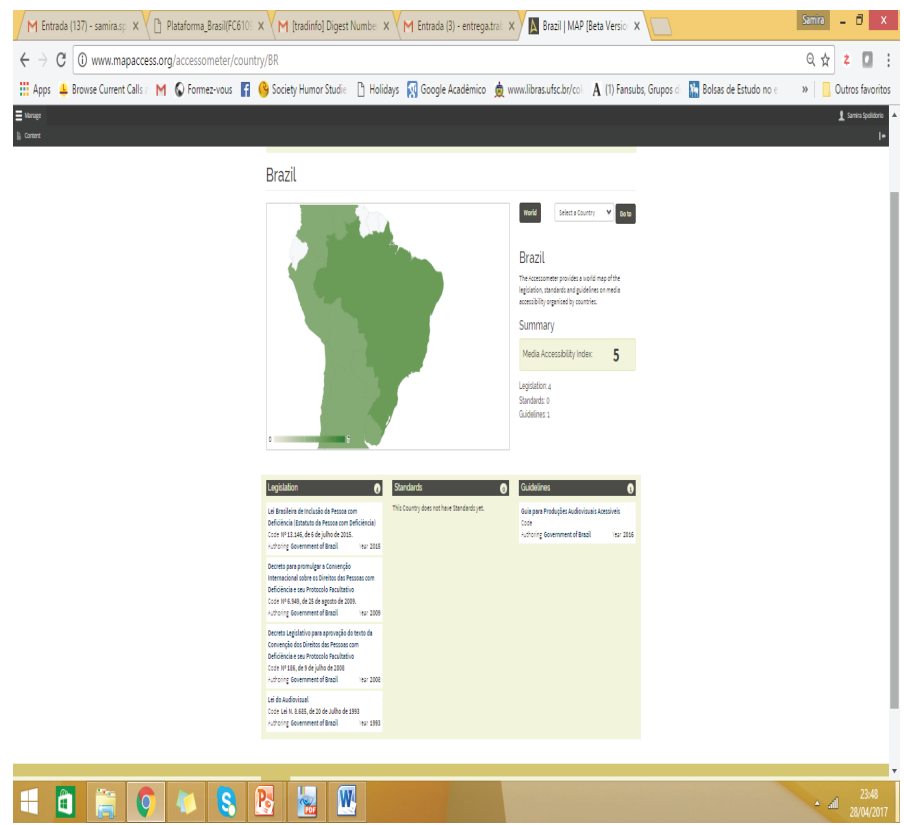

Figura 4. captura de tela da página do Brasil no Acessômetro em 28/04/2017 Fonte: a autora

Ao clicarmos em um dos itens apresentados, mais informações relativas àquele item são apresentadas como título em língua original, tradução do nome para o inglês, tipo de item do Acessômetro (legislação, padronização ou orientação), código de identificação (se houver), autoria, ano de publicação, país, link para acesso pela internet, nome do colaborador que inseriu a informação e data da inclusão do item no banco de dados.

Para facilitar o agrupamento e categorização dessa informação e torna-la pesquisável dentro da plataforma, todas as modalidades de acessibilidade midiática tratadas no documento também são listadas (ver adiante sobre as diferentes modalidades), bem como as palavras-chave que ajudam a ferramenta de busca a encontrar o conteúdo armazenado na plataforma.

Como exemplo, podemos ver as imagens abaixo, que apresentam o Guia para Produções Audiovisuais Acessíveis e a Lei do Audiovisual, com as respectivas informações de cada item. 


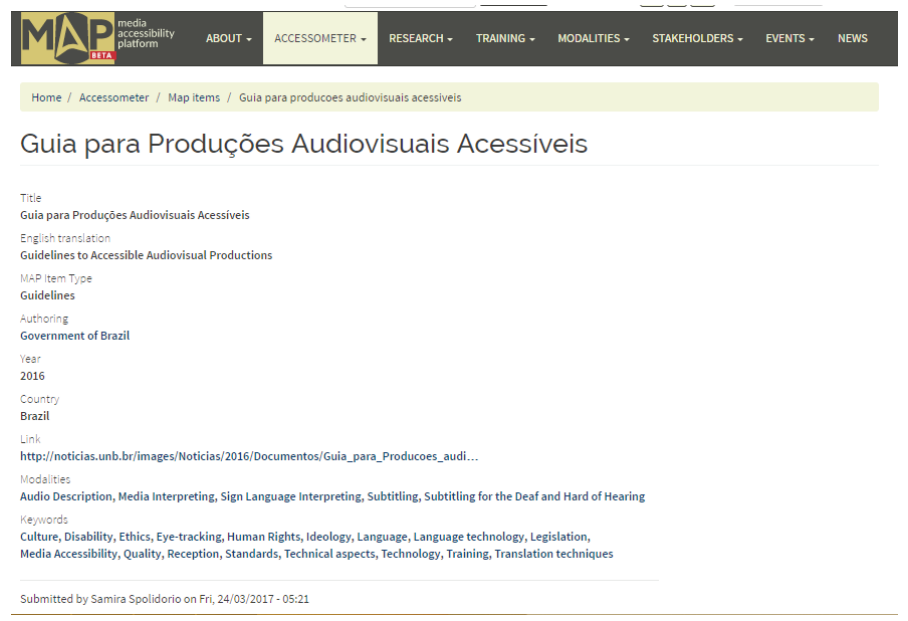

Figura 5. captura de tela da página de item do Acessômetro em 28/04/2017 Fonte: a autora

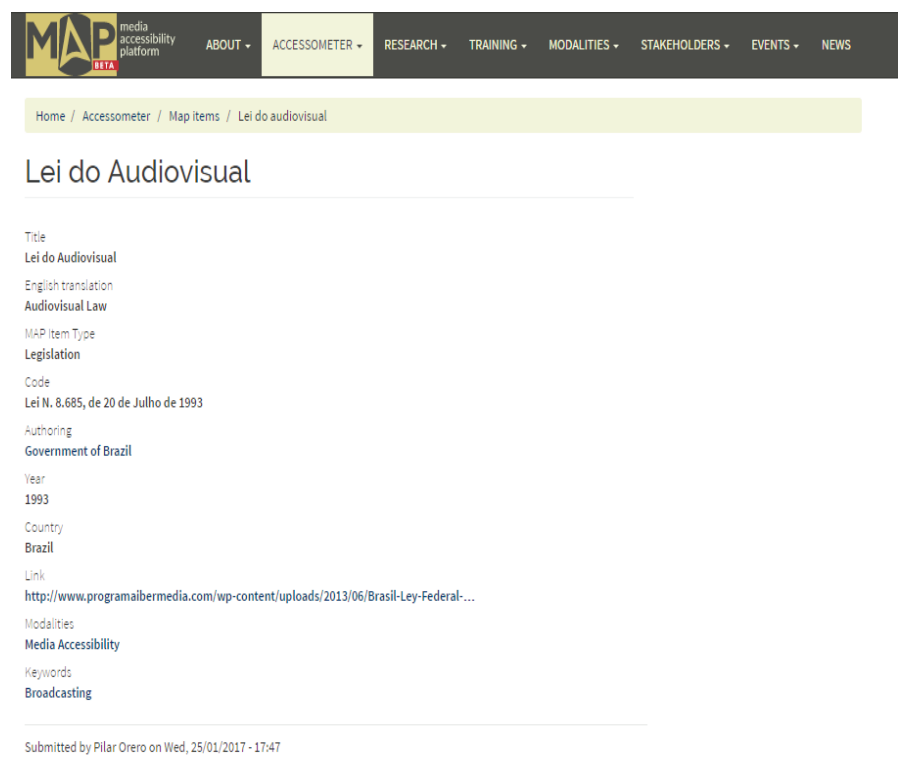

Figura 6. captura de tela da página de item do Acessômetro em 28/04/2017 Fonte: a autora

Embora ainda incompleto no que se refere à abrangente legislação brasileira sobre acessibilidade, o Acessômetro é a categoria da MAP que, proporcionalmente, 
encontra-se mais bem representada. Isso significa dizer que, mesmo que menos da metade dos itens de legislação ainda não tenham sido incluídos, a relação entre a quantidade total de itens existentes e a quantidade já inserida ainda é bem maior do que nas outras categorias.

Por exemplo, no que diz respeito à aba de Pesquisa, área em que o Brasil apresenta uma produção ampla e relevante, pouco conteúdo encontra-se inserido na plataforma. Entre os livros incluídos, temos o recém-lançado "Acessibilidade audiovisual: produção inclusiva nos contextos acadêmicos e nas plataformas da web", organizado por Lucinéa Villela (2017), em cuja tela de apresentação consta, inclusive, um resumo da apresentação do livro e o link para o download gratuito:

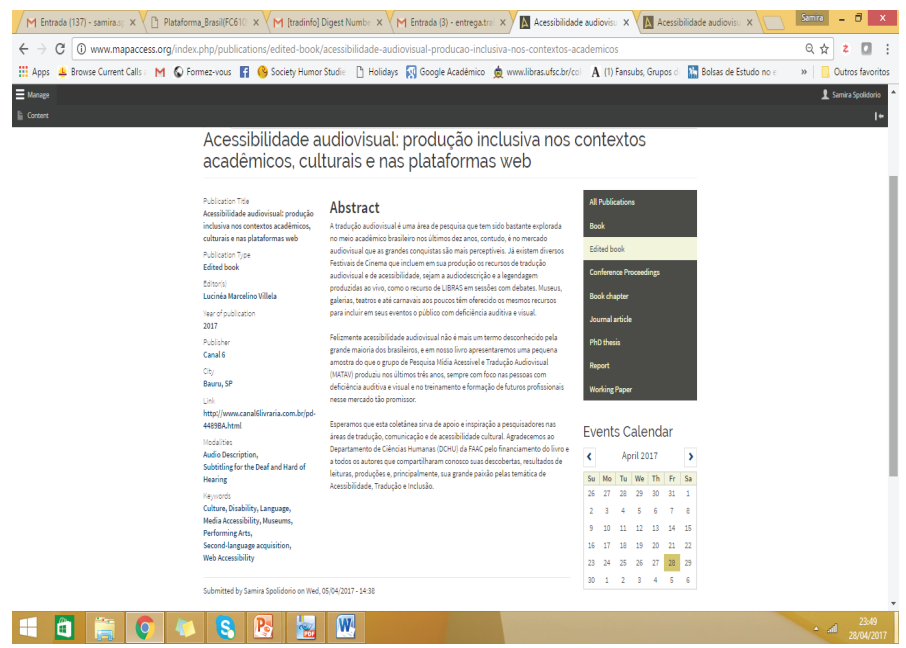

Figura 7. captura de tela da página do item Livro editado em Pesquisa em 28/04/2017 Fonte: a autora

O livro "Os Novos Rumos da Pesquisa em Audiodescrição no Brasil" organizado por Vera Lucia Santiago Araújo e Marisa Aderaldo, publicado em 2013 -, também está inserido. Porém, estão de fora muitos outros livros importantes como o "Livro da audiodescrição: transformando imagens em palavras" - de Lívia Maria Villela de Mello Motta e Paulo Romeu Filho, lançado em 2010 -, e "Audiodescrição: práticas e reflexões", organizado por Daiana Stockey Carpes em 2016, para citar apenas exemplos de livros relacionados à modalidade de audiodescrição.

Há ainda uma grande produção nacional relativa a outras modalidades - como a legendagem e a dublagem, a legendagem para surdos e ensurdecidos, a janela de 
LIBRAS e a interpretação de LIBRAS em si, a acessibilidade às páginas da internet etc. (trataremos dessa variedade de modalidades mais adiante neste artigo) -, que também não está contemplada na plataforma e seria importante contribuição para o banco de dados que se pretende estabelecer com a criação da MAP.

E muito dessa relevante produção nacional encontra-se disponível em versão digital e de forma gratuita na internet por se tratarem de dissertações de mestrado, teses de doutorado e, principalmente, artigos publicados em periódico, o que torna ainda mais importante a divulgação e propagação desse conteúdo. Com exceção de alguns poucos artigos de periódicos, não há entradas ainda para relatórios, teses, dissertações e outras formas de produção bibliográfica além dos poucos livros e capítulos mencionados neste artigo.

Devido à plataforma ser um banco de dados mundial, não é possível filtrar livros e artigos apenas usando o país, uma vez que um livro ou artigo pode, por exemplo, ser escrito por autores de um país, mas ser editado por organizadores de outros países e ser efetivamente publicado em periódicos e por editoras de outros países ainda. Assim, a forma mais direta de encontrar as publicações de autores brasileiros para a investigação pretendida neste artigo foi buscar pelas palavraschave em língua portuguesa.

Contudo, essa estratégia apresenta também resultados referentes a conteúdo de outros países de língua portuguesa, como é o caso do livro "Vozes que se vêem: Guia de Legendagem para Surdos" da pesquisadora portuguesa Josélia Neves, publicado em 2007 pelo Instituto Politécnico de Leiria, da Universidade de Aveiro, em Portugal.

Assim, tentou-se buscar pelo nome em específico de proeminentes pesquisadores brasileiros na área de tradução audiovisual e, dentre os resultados, destaca-se Vera Lúcia Santiago Araújo, com seis entradas, e Eliana Paes Cardoso Franco, com cinco entradas, como apontam as imagens abaixo: 


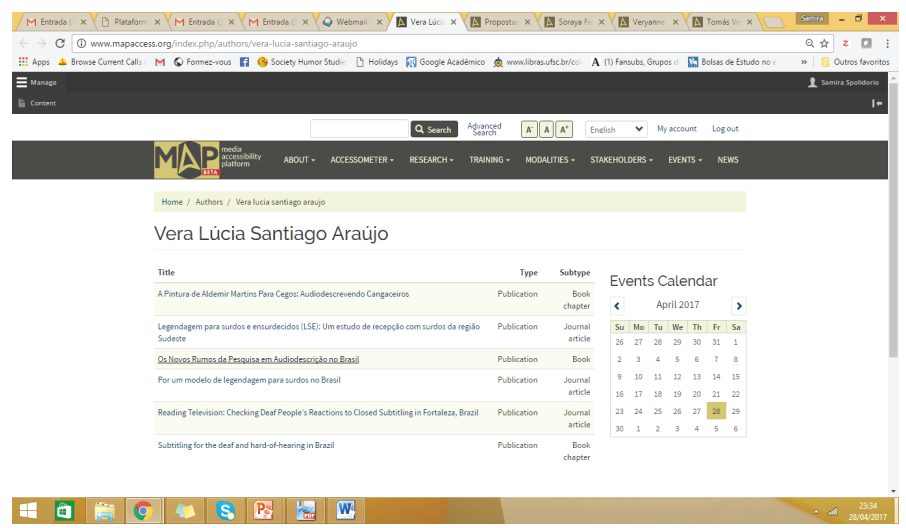

Figura 8. captura de tela da página de resultados da busca por autor em 28/04/2017 Fonte: a autora

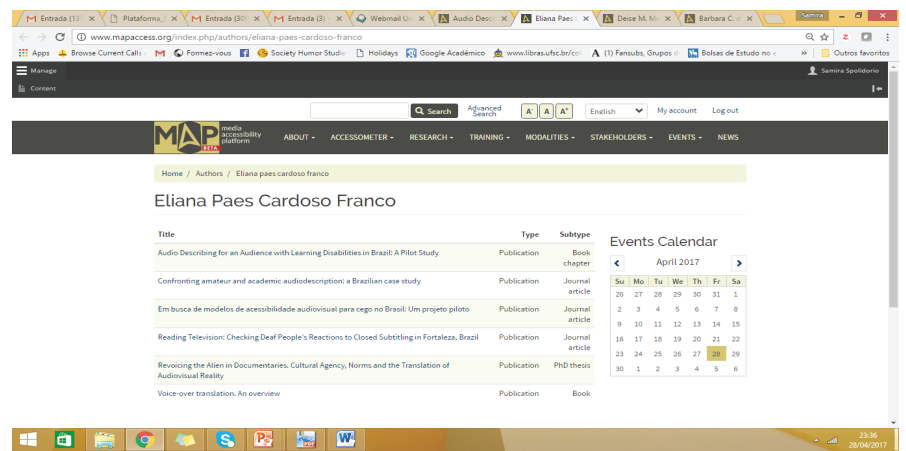

Figura 9. captura de tela da página de resultados da busca por autor em 28/04/2017 Fonte: a autora

Contudo, uma busca simples no currículo Lattes dessas autoras mostra uma extensa e relevante lista de publicações que não estão incluídas, entre livros, capítulos, artigos, resumos expandidos de apresentações em congressos e conferências, etc. Inclusive, é importante mencionar que boa parte da produção bibliográfica de Eliana Franco encontra-se disponível em língua inglesa, o que facilitaria ainda mais sua divulgação caso esses dados estivessem disponíveis na MAP.

Entre outros pesquisadores brasileiros que aparecem na busca da MAP, temos Lucinéa Marelino Villela, com duas entradas, ainda que sua produção bibliográfica na área seja também muito extensa e pertinente. 


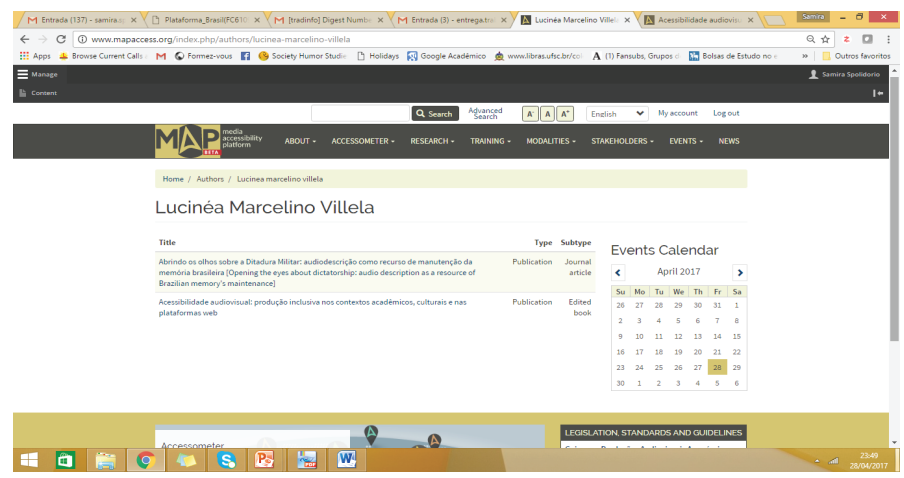

Figura 10. captura de tela da página de resultados da busca por autor em 28/04/2017 Fonte: a autora

Já outras pesquisadoras de renome no cenário brasileiro, como Soraya Ferreira Alves e Lívia Maria Villela de Mello Motta, aparecem com apenas uma entrada no banco de dados da MAP, embora apresentem também significativa produção bibliográfica na área enquanto outros muitos pesquisadores com relevantes contribuições sequer aparecem como autores listados.

Apenas como referência, a busca simples por pesquisadores brasileiros com título de doutor que tenham inserido a palavra-chave "tradução audiovisual" em seus currículos Lattes produziu 572 entradas, como mostra a imagem abaixo:

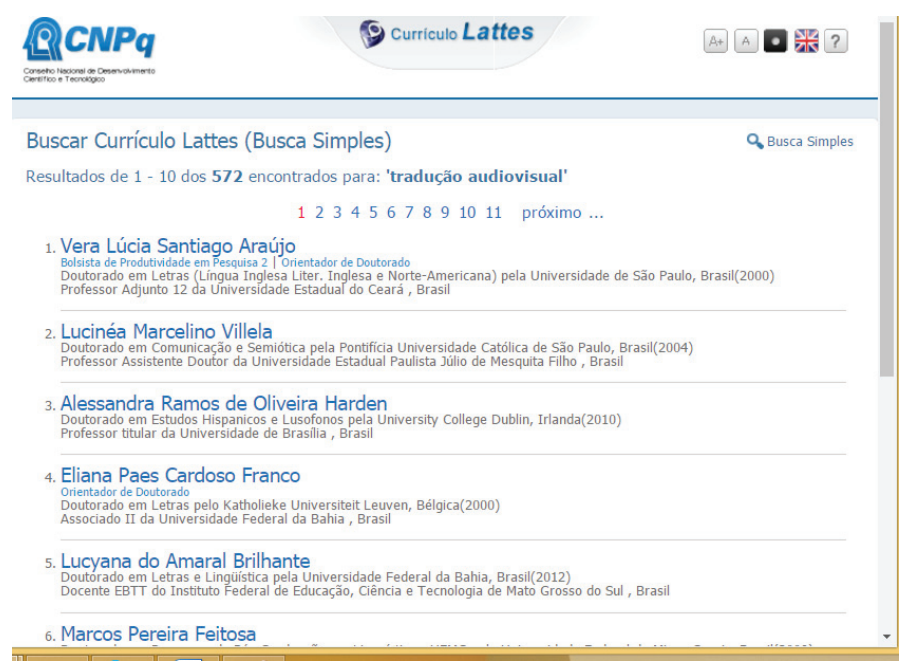

Figura 11. captura de tela da página de resultados da plataforma Lattes em 28/04/2017 Fonte: a autora 
Dentre os primeiros nomes que aparecem na extensa lista de pesquisadores brasileiros, temos as já mencionadas professoras Vera Lúcia Santiago Araújo e Lucinéa Marcelino Villela e a pesquisadora Eliana Paes Cardoso Franco, mas os outros três pesquisadores que aparecem em destaque na plataforma Lattes devido a sua atuação e produção bibliográfica na área não aparecem listados na MAP.

Uma vez que a organização do Currículo Lattes obedece um criterioso modo de organização entre as diferentes formas de publicação, o conteúdo presente no currículo desses pesquisadores é um frutífero banco de dados para encontrar conteúdo relevante para ser inserido na MAP por meio do projeto de pesquisa "MAPeando a acessibilidade de audiovisual no Brasil e alimentando a plataforma global de acessibilidade midiática (MAP)", ainda a ser apresentado mais adiante.

Já no que se refere ao acesso por meio da aba Modalidades, esta traz uma mistura dos itens apresentados nas outras abas, como, por exemplo, publicações, legislações, treinamentos, eventos, notícias, etc., mas filtrando-os pelas modalidades presentes. São apresentadas não só as modalidades para acessibilidade para pessoas com deficiências visual e auditiva, mas também a acessibilidade linguística proporcionada pelas modalidades de tradução audiovisual.

Além das modalidades definidas por Araújo e Franco (2011) e apresentadas na seção anterior deste artigo (Legendagem para Ouvintes, Legendagem para Surdos e Ensurdecidos, Legendagem Eletrônica, Dublagem, Voice-over e Audiodescrição), a MAP considera também:

- Accessible Filmmanking (Produção Cinematográfica Acessível), que é acessibilidade como parte integrante da produção, em que a audiodescrição e a legendagem para surdos e ensurdecidos é levada em conta desde os estágios iniciais da elaboração do roteiro e filmagem das cenas, e não apenas como uma atividade posterior quando o filme já está completo;

- Audio subtitling (Leitura de Legendas), que é a leitura em voz alta e ao vivo das legendas de um filme, programa de televisão ou outro evento cultural, podendo ser feita de forma computadorizada e ou por profissionais da dublagem e/ ou do teatro;

- Media Interpreting (Interpretação Midiática), que envolve uma série de possibilidades de interpretação simultânea de produtos midiáticos e/ou audiovisuais;

- Respeaking (Revocalização), em que profissionais repetem o texto falado para a captação do software que cria as legendas do closed-caption,

- Sign Language Interpreting (Interpretação de Língua de Sinais), que usa a Língua Americana de Sinais (ASL) ou a Língua Brasileira de Sinais (LIBRAS), por 
exemplo, tanto em eventos ao vivo quanto em programas midiáticos e produtos audiovisuais;

- Media Accessibility (Acessibilidade Midiática), termo guarda-chuva que abarca todas as modalidades acima, além de outras adaptações e funcionalidades que visam proporcionar a acessibilidade linguística ou para pessoas com deficiência a conteúdo midiático.

Todas as modalidades contempladas pela MAP podem ser vista na imagem abaixo:

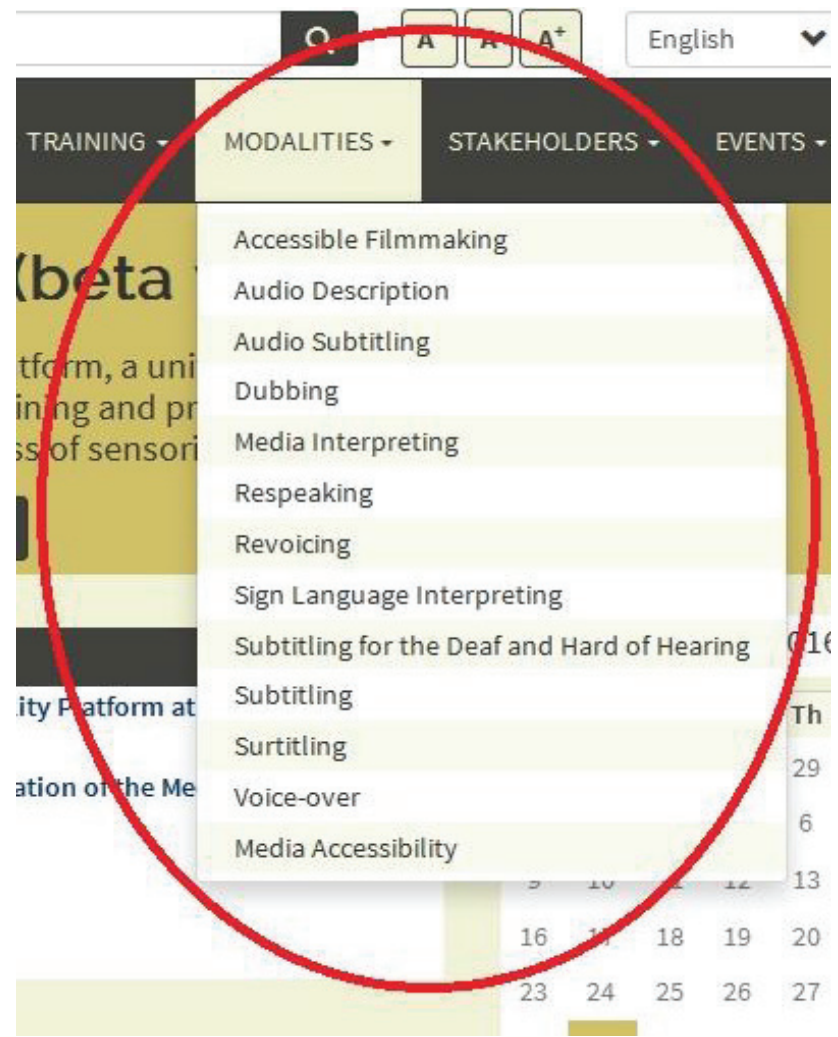

Figura 12. captura de tela da aba Modalidades do site da MAP Fonte: Greco et al., (2016)

A aba de Treinamento, um item de suma importância para a formação de profissionais aptos e capacitados, apresenta um total de apenas 15 cursos oferecidos presencialmente e à distância por universidades e instituições em países como 
Espanha, Noruega e Reino Unido, mas nenhum curso universitário, online ou profissionalizante do Brasil.

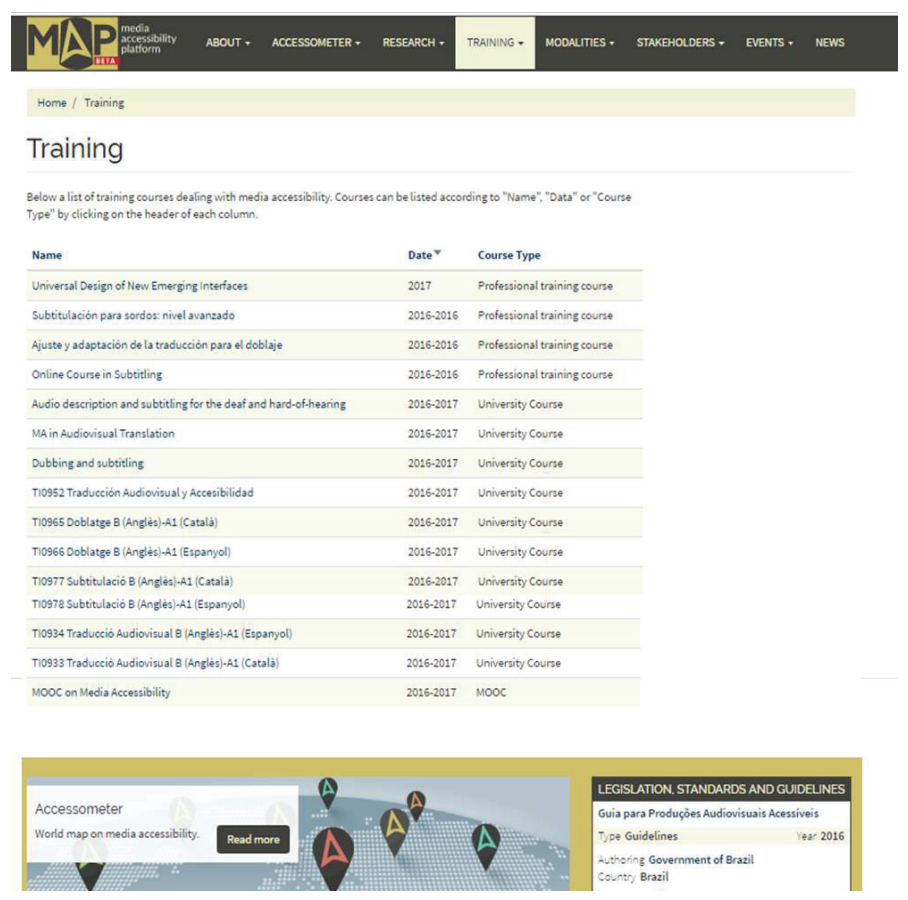

Figura 13. captura de tela da aba Treinamento do site da MAP em 28/04/2017 Fonte: a autora

Uma busca rápida no Google apresenta a existência, no Brasil, de uma variedade enorme não só de cursos universitários (de graduação, pós-graduação e extensão), mas também de cursos livres ministrados por profissionais da área e outras instituições/organizações (como a Escola de Tradutores, a Brasilis, Gemini Translation), existentes nas modalidades presencial e online, que tratam das várias modalidades de tradução audiovisual e tradução audiovisual acessível. No entanto, nenhum deles está inserido na plataforma até o momento da elaboração desse artigo.

Outra aba, ainda em construção, é a aba Partes Interessadas, que é subdividida em 'Instituições' e 'Associações', mas até a revisão final deste trabalho ainda não disponibilizava nenhuma informação de nenhuma associação ou instituição. A saber, temos no Brasil a Associação Brasileira de Tradutores (ABRATES), o Sindicato Nacional dos Tradutores (SINTRA) e a Associação Brasileira de Pesquisadores 
em Tradução (ABRAPT), nas quais a representatividade da classe profissional e acadêmica tem crescido bastante nos últimos anos.

Já a aba de Eventos apresenta quatro eventos ocorridos no final de 2016, depois do lançamento da plataforma, e nove eventos programados para 2017. É possível organizar a visualização das entradas por data específica e escolher ordem crescente ou decrescente, como pode ser visto na imagem abaixo:

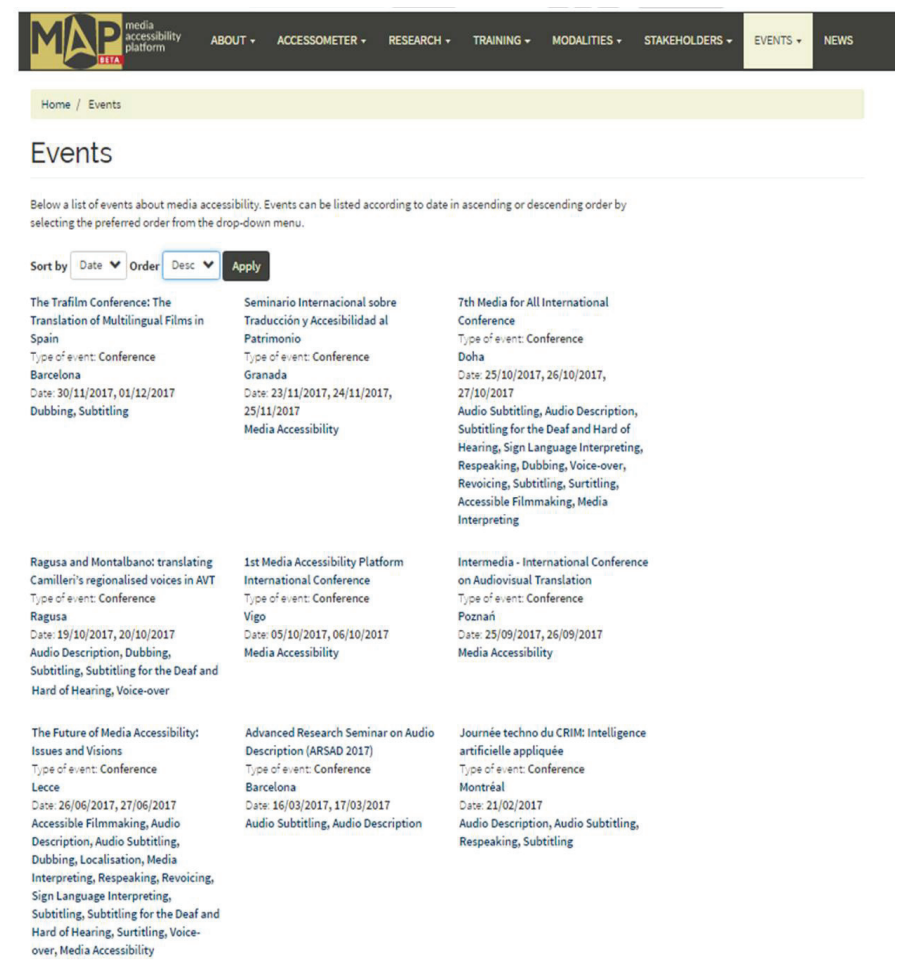

Figura 14. captura de tela da aba Eventos do site da MAP em 28/04/2017

Fonte: a autora

O Brasil tem um calendário acadêmico repleto de congressos, conferências, encontros, seminários de nível nacional e internacional, em que a tradução audiovisual e a tradução audiovisual acessível estão recebendo cada vez mais destaque. Então, incluir nossos eventos acadêmicos também nessa aba seria contribuição bastante relevante para a MAP. Um exemplo é o evento anual organizado pela Universidade Estadual Paulista "Júlio de Mesquita Filho" (Unesp) de São José do Rio Preto, a Semana do Tradutor, que em 2017 está em sua $37^{\mathrm{a}}$ edição, sendo a 
Tradução Audiovisual uma das 11 áreas temáticas que serão abordadas, tanto por conferencistas convidados quanto em apresentações de comunicação oral para divulgação de pesquisas desenvolvidas ou em desenvolvimento na área.

Apesar de muitos outros eventos acadêmicos, o Brasil recebe também congressos com um foco mais voltado para o mercado, como por exemplo, a Conferência Brasileira dos Tradutores do PROZ.com, realizada em Curitiba em 2016, ou ainda o Congresso da ABRATES, que em 2017 terá uma sala de conferências especialmente dedicada à Tradução Audiovisual (batizada de "Netflix and Chill" com 11 palestras na área, abordando temas tanto das modalidades mais comuns de tradução audiovisual, como a legendagem e a dublagem, quanto da tradução audiovisual acessível por meio de palestras sobre a audiodescrição e a legendagem eletrônica).

A última aba, Notícias, tem o potencial de ser uma das mais interativas, trazendo notícias do mundo todo sobre novos cursos, publicações, eventos, além de outras novidades relacionadas à acessibilidade midiática. Contudo, até o momento, apenas quatro notícias de 2016 foram incluídas. Com isso, podemos perceber que, mesmo dentre os países com maior representatividade na MAP, nem todos os itens são atualizados com a mesma frequência, pois mesmo os dados da Espanha e Itália países onde os idealizadores atuam profissionalmente e, portanto, têm mais acesso ao conteúdo a ser disponibilizado na MAP -, ainda estão sendo alimentados aos poucos.

Como explicado anteriormente, a primeira fase do projeto MAP visava colocar a plataforma em funcionamento efetivo e iniciar a divulgação do projeto para que os dados iniciais pudessem ser coletados e inseridos na plataforma pelos idealizadores e os colaboradores. Na segunda fase, ser iniciada em maio de 2017, espera-se aumentar o número de colaboradores para que novos pesquisadores possam contribuir incluindo não só suas próprias pesquisas e publicações, mas também ajudar coletando dados de colegas e inserindo-os na plataforma.

Nesse esforço, o grupo de pesquisa "Tradução Audiovisual: quebrando barreiras linguísticas e de acessibilidade ${ }^{\prime 4}$ da Universidade Metodista de Piracicaba (Unimep) tem docentes e discentes envolvidos na compilação de alguns itens pertencentes à aba Acessômetro (em especial, o item legislação) e à aba Pesquisa (mais especificamente os grupos de pesquisa e as teses de doutorado publicadas), que serão posteriormente inseridos na plataforma.

4. http://dgp.cnpq.br/dgp/espelhogrupo/5535684885493650 
A saber, o projeto de pesquisa intitulado "MAPeando a acessibilidade audiovisual no Brasil e alimentando a plataforma global de acessibilidade midiática (MAP)" desenvolvido pelo grupo tem como objetivos:

\section{Objetivos gerais:}

- divulgar entre o corpo discente do curso de Letras Inglês - Tradução e Interpretação e também de outros cursos da instituição a importância da acessibilidade audiovisual;

- apresentar a tradução audiovisual acessível como importante área de estudo dentro dos Estudos da Tradução, que se encontra em crescente desenvolvimento;

Objetivos específicos:

- mapear a produção brasileira de conteúdo sobre acessibilidade midiática da legislação (leis e decretos nas esferas municipais, estaduais e federais) e de pesquisas acadêmicas na área incluindo projetos em andamento e pesquisas já concluídas e publicadas;

- mapear o oferecimento de oportunidades de treinamento e formação profissional por meio de cursos sobre tradução audiovisual acessível para atender a crescente demanda criada pela legislação brasileira;

- mapear a cobertura da mídia sobre o assunto acessibilidade audiovisual por meio de reportagens e notícias publicadas em jornais, revistas, blogs, páginas da internet e outros veículos midiáticos;

- compilar e incluir os dados mencionados acima na MAP (UNIMEP, 2017);

Contudo, mesmo que docentes e discentes do grupo estejam se dedicando ao levantamento dos dados relativos à aba Acessômetro e de alguns itens da aba Pesquisa, ainda há uma quantidade enorme de dados possíveis de serem compilados e inseridos nas outras abas e categorias, sendo necessária a contribuição de um grande número de participantes para garantir a divulgação do conteúdo sobre tradução audiovisual e acessibilidade midiática produzido no Brasil.

Embora o cadastro para colaboradores da MAP seja simples e o processo de inserção dos dados fácil (ainda que consuma um tempo considerável por ser uma inserção manual), o risco de inserções duplicadas de entradas na plataforma e, consequentemente, de desperdício de tempo, é grande se não houver uma organização e alguma forma de verificação centralizada dos dados já compilados e inseridos, o que está sendo feito pelo grupo "Tradução Audiovisual: quebrando barreiras linguísticas e de acessibilidade". 
Assim, a bem-vinda parceria ${ }^{5}$ com outras universidades, pesquisadores e grupos de pesquisa interessados em colaborar na compilação e inserção dos dados referentes à produção brasileira sobre tradução audiovisual acessível. Assim, será possível prevenir que os problemas da "Biblioteca de Babel" e o efeito da "Reinvenção da Roda" mencionados pelos criadores da MAP sejam reproduzidos também em âmbito nacional.

\section{CONSIDERAÇÕES FINAIS}

A intenção deste artigo foi destacar a importância da acessibilidade midiática e da frutífera produção brasileira a respeito da tradução audiovisual acessível, alertando para o desequilíbrio entre a quantidade de conteúdo efetivamente produzido e a visibilidade e o prestígio em âmbito internacional de nossas pesquisas e pesquisadores.

Ao apresentar a legislação nacional e internacional que garante o direto à acessibilidade das pessoas com deficiências, pretendeu-se mostrar como esse assunto não é apenas de interesse da academia, mas também um fator social e legal de muita relevância no país e no mundo.

Em consonância com esses avanços - tanto sociais e mercadológicos quanto acadêmicos na área da acessibilidade midiática -, a proposta da criação da MAP foi de ser um banco de dados centralizador dessas informações, facilitando a pesquisa e o acesso a essas importantes informações.

Contudo, muito da produção brasileira, tanto legal quando acadêmica, ainda precisa ser inserida na plataforma e, portanto, também foi intuito desse artigo divulgar a plataforma e apresentar suas características básicas na esperança de mobilizar mais pesquisadores da área a contribuir para a compilação e inserção de dados sobre o Brasil, particularmente, associando-se ao grupo "Tradução Audiovisual: quebrando barreiras linguísticas e de acessibilidade" no âmbito do projeto "MAPeando a acessibilidade audiovisual no Brasil e alimentando a plataforma global de acessibilidade midiática (MAP)".

5. Interessados podem entrar em contato com a coordenadora do grupo pelo email institucional sispolid@unimep.br 


\section{REFERÊNCIAS BIBLIOGRÁFICAS}

ANCINE. Plano de Diretrizes e Metas para o Audiovisual. 2013. Disponível em <http://www. recam.org/_files/documents/pdm_2013.pdf> Acesso em 15 de abril de 2017.

BRASIL. Lei $n^{0}$ 4.117, de 27 de agosto de 1962. Disponível em <http://www.planalto.gov.br/ ccivil_03/leis/L4117.htm> Acesso em 15 de abril de 2017.

BRASIL. Decreto $n^{0}$ 5.296, de 2 de dezembro de 2004. Disponível em < http://www2.camara.leg.br/ legin/fed/decret/2004/decreto-5296-2-dezembro-2004-534980-normaatualizadape.html> Acesso em 20 de abril de 2017.

BRASIL. Lei $n^{0}$ 12.343, de 2 de dezembro de 2010 sobre Plano Nacional da Cultura. Disponível em $<$ http://www.cultura.gov.br/documents/10907/963783/Lei+12.343+ + PNC.pdf/ e9882c97-f62a-40de-bc74-8dc694fe777a > Acesso em 20 de abril de 2017.

BRASIL. Decreto Legislativo $N^{0}$ 186, de 2008. Disponível em <http://www.planalto.gov.br/ ccivil_03/constituicao/congresso/DLG/DLG-186-2008.htm> Acesso em 20 de abril de 2017.

BRASIL. Decreto $n^{0}$ 6.949, de 25 de agosto de 2009. Disponível em < http://www.planalto.gov. br/ccivil_03/_ato2007-2010/2009/decreto/d6949.htm> Acesso em 20 de abril de 2017.

BRASIL. Portaria 188 de 2 de dezembro de 2010. Disponível em < http://www.portaldeacessibilidade. rs.gov.br/legislacao/4/388> Acesso em 20 de abril de 2017.

BRASIL. Lei $n^{0}$ 13.146, de 6 de julbo de 2015. Disponível em <http://www.planalto.gov.br/ ccivil_03/_ato2015-2018/2015/lei/113146.htm > Acesso em 20 de abril de 2017.

DIAZ-CINTAS, J.; REMAEL-ROUTLEDGE, A. Audiovisual Translation, Subtitling: Translation Practices Explained. Nova Iorque: Routledge, 2007.

DIAZ CINTAS, J.; NEVES, J. Taking Stock of Audiovisual Translation. In DIAZ CINTAS, J.; NEVES, J. Audiovisual Translation Taking Stock. 2015. Disponível em: < http://www. cambridgescholars.com/download/sample/62424>.

FRANCO, E. C. P.; ARAUJO, V. S. Questões Terminológico-conceituais no campo da tradução audiovisual. Tradução em Revista. n.11, 2011. Disponível em: < https://www. maxwell.vrac.puc-rio.br/18884/18884.PDFXXvmi=>. Acesso em 25/11/2016 
GAMBIER, Y. (Multi) Media Translation: concepts, practices and research. Philadelphia, PA, USA: John Benjamins Publishing Company, 2001.

GRECO, G.M. On Accessibility as a Human Right, with an Application to Media Accessibility. In: MATAMALA, A.; ORERO, P. (eds.) Researching Audio Description. Palgrave: New Approaches, 2016, pp. 11-33.

NAVES, S. B.; MAUCH, C.; ALVES, S. F.; ARAÚJO, V. L. S. (Org.). Guia Para Produções Audiovisuais Acessíveis. Brasília: Secretaria do Audiovisual do Ministério da Cultura, 2016.

ORERO, P. Topics on Audiovisual Translation. Amsterdam/Philadelphia: John Benjamins Publishing Company, 2004.

PINERO, R. B. \& DIAZ-CINTAS, J. Introduction. In: PINERO, R. B. \& DIAZCINTAS, J. Audiovisual Translation in Global Context: Mapping an ever-changing landscape. London: Palgrave Macmillan UK, 2015. Disponível em: <https:/www.academia. edu/31944767/2015_-_Audiovisual_Translation_in_a_Global_Context $>$ Acesso em 26/03/2017.

ROMERO-FRESCO, P. Accessible filmmaking: Joining the dots between audiovisual translation, accessibility and filmmaking. The Journal of Specialized Translation. Issue 20, 2013. Disponível em: <http://www.jostrans.org/issue20/art_romero.php>.

UNIMEP. MAPeando a acessibilidade audiovisual no Brasil e alimentando a plataforma global de acessibilidade midiática (MAP). Projeto de Pesquisa do Fundo de Apoio à Pesquisa. Piracicaba: Faculdade de Ciências Humanas-UNIMEP, 2017.

Recebido: 08/05/2017

Aceito: 08/07/2017 